\title{
CLINICAL STUDY OF TRADITIONAL CHINESE MASSAGE COMBINED WITH MUSIC THERAPY IN TREATMENT OF CEREBRAL PALSY
}

\author{
Z. Liu \\ Cerebral Palsy Rehabilitation Centre, Nanhai Affiliated Hospital for Women and Children, Guangzhou \\ University of Chinese Medicine Guangdong, Foshan Nanhai, China
}

Objective: Clinical observation of traditional chinese massage combined with music therapy to improve lower limbs' range of motion(ROM) and to reduce score of composite spasticity scale(CSS) in children with cerebral palsy $(\mathrm{CP})$.

Methods: Traditional chinese massage was performed to children with CP, such as to attack vital points of DU meridian, to tonify qi of kidney and slpeen, pinching massage, footplate massage, and segmental massage. Background music was played at the same time. Course of treatment was 30 days. ROM of anklejoint and hip-joint, score of CSS was measures before and after the treatment.

Results: 286 children with CP paticipated. 106 cases showed significant effect(37.40\%), 172 cases showed progress $(59.16 \%)$, and 8 cases had no-effect(2.84\%). Significant improvement were found after treatment for ROM of ankle-joint(bofore: 105.64 \pm 12.66 ; after: 76.58 \pm 9.89 ), and ROM of hip-joint(bofore: $119.89 \pm 25.47$; after: $158.99 \pm 18.66)(\mathrm{P}<0.01)$. Score of CSS was significantly lower after treatment(before: $12.39 \pm 2.56$; after: 7.069 \pm 2.97$)(\mathrm{P}<0.01)$.

Conclusion: Traditional chinese massage combined music therapy can regulate qi and blood, solute muslce contracture and spasm, so as to rectify scissors gait and talipes, to improve gross motor function of children with CP. It is a therapy of convenience, economy and benefit. 